\title{
Uncertainty in Digital Platforms and Ecosystems: The Dynamic Interplay Between Knowledge Problems
}

\author{
Amal Alsahli \\ Case Western Reserve University \\ amal.alsahli@case.edu
}

\author{
May Bantan \\ Nova Southeastern University \\ $\underline{\text { mb2627@mynsu.nova.edu }}$
}

\begin{abstract}
The information systems literature has long argued that innovation drives uncertainties in organizations. While extant research has extensively studied knowledge problems in the traditional firm setting and their implications on organizing and decision making, an updated understanding is required in relation to uncertainties within digital platforms and ecosystems, where organizational boundaries are blurred and downstream movement is becoming more popular. To address this issue, we explore the different dimensions of uncertainties in the digital platforms and ecosystems by classifying them based on the knowledge problems that dominantly contribute to their formation and the platform actors facing such uncertainties. A higherlevel uncertainty emerges as a result of the interactions within these dimensions. In addition, the interactions evolve in longitudinal and dynamic patterns due to the complex nature of digital platforms and ecosystems.
\end{abstract}

\section{Introduction}

Digital platforms and ecosystems have been transforming today's business landscape. Constantinides, Henfridsson, and Parker define digital platforms as "a set of digital resources - including services and content - that enable value-creating interactions between external producers and consumers" [1: p. 381]. These resources and interactions are organized in a larger ecosystem, which, in this case, represents the alignment structure of the multilateral set of actors materializing the value [2]. Platform-based firms such as Amazon, Google, or Facebook utilize information and communication technologies by which multiple actors (e.g., platform owners, users, regulators) interact at different levels in a complex, evolutionary, and dynamic fashion. As a result, uncertainties arise in the form of persistent and pervasive challenges facing the digital platform and its actors.
Research in the field of entrepreneurship has identified that these uncertainties are driven by different types of knowledge problems that new ventures face, including ambiguity, equivocality, and complexity [3]. Despite the growing number of studies on the innovation dynamics in digital platforms [4]-[6], it is still unclear how the uncertainties associated with platform innovation emerge from different forms of knowledge problems as interpreted by the platform actors. The goal of this paper is to address this gap within the current literature by answering the following research question:

How has the emergence of platforms and ecosystems as an avenue for innovation changed the nature and conceptualization of uncertainty?

To answer this question, we synthesize the current literature in the fields of digital platforms and innovation uncertainty and develop a set of theoretical propositions to understand the role of knowledge problems as drivers of uncertainties among actors in digital platforms and ecosystems. We conclude with a set of questions that outline a future research agenda. Our research contributes to the digital platform literature in three different ways. First, this paper critically builds on a recent review of knowledge problems in the entrepreneurship domain [3] and extends the conversation into the digital platform context. In doing so, we clarify the different sources of uncertainty in digital platforms and ecosystems. Second, the paper presents platform uncertainty as a multidimensional higher-level concept where different platform actors deal with different dimensions of uncertainty in a dynamic and interactive manner. Lastly, we provide a comprehensive research agenda that addresses the sources and dimensions of uncertainty, taking into consideration the structural and organizational challenges of digital platforms and ecosystems. 


\section{Literature review}

\subsection{Digital platforms and ecosystems}

Platforms have captured the attention of a wide array of strategy, economics, and information systems researchers over the last decades. From a strategy perspective, the discussions of platforms focus on the idea of modularity where an architecture design of core and periphery is essential to stimulate innovation and new product development [7], [8]. The utilization of this architectural design has been extended from being an internal production capability to an external open innovation lever [9], [10].

From an economics perspective, platforms are special kinds of markets that facilitate an exchange among end-users. The concept of external platforms supplying innovative products is similar to that of multisided markets in the economics literature [11]-[14]. Both strategy and economics research emphasize the importance of network effects. Network effects or network externalities [15], [16] have been closely associated with platforms in which the increased number of platform users has an impact on the value created for each user [17], [18]. Whereas positive network effects refer to the ability of a large, wellmanaged platform community to generate significant value for each user of the platform, negative network effects indicate the possibility that a growing, yet poorly managed, platform community can diminish the value produced for each user [19]. In addition, there could be the issue of network congestion resulting from an undesired increase in the network size. These positive or negative network effects have also been classified as being direct, benefiting the same side of the platform, or indirect, benefiting the platform's cross sides [20].

Although industry platforms or multi-sided markets are built to exploit the collective technological, social, and economic values via resource optimization [21], some interactions among the platform actors may result in negative externalities. According to Parker et al. [19], negative externalities are one of the main causes of market failure. In their view, along with Cohen and Sundararajan's [22], negative externalities occur when a given interaction results in unintended spillover costs. Evans [23] examined the causes of negative externalities and recognized their effects on the interacting actors. The causes he observed ranged from fraud, misrepresentation, and other opportunistic or offensive behaviors to poor and asymmetric information.

From the perspective of information systems research, the majority of platform discussions revolve around managing digital ecosystems, most specifically a software ecosystem, where software-based platforms are open to third-party developers [24]. In general, platform-based businesses need to have the "right level" of governance in order to function optimally. Tiwana et al. [4] labeled this issue of balance the "Goldilocks Governance Problem" where the platform sponsor is challenged to maintain sufficient control on the platform activities in order to oversee its integrity and functionality, and, at the same time, loosen enough control to allow for flexible interactions among actors or autonomy among independent developers. Careful design for the boundary resources such as application programming interfaces (API) helps platform owners understand the tension between opening and controlling the platform [25].

The review of platform research in the different streams of literature shows the central role of the network effect in maximizing the value of the platform. The optimization of the network effect in the strategy and information systems literature is mainly a question of creating efficiency and open innovation, while in economics, it is a question of balancing the network size.

The diversity in the digital platform literature leaves us with a wide variety of digital platform classifications. As noted by Kenney and Zysman [26], the proliferation of labels used to describe platforms and the new economy built on these platforms is a mere reflection of their significant consequences for society, markets, and firms.

In this paper, we adopt a general classification of digital platforms based on their main functions: transaction and innovation [27]. Transaction platforms facilitate exchange or transaction among the platform's users. Examples include Uber, Airbnb, and Amazon Marketplace. On the other hand, innovation platforms facilitate innovation by allowing "complementors," external users producing complementary goods and services, to innovate using the platform's core technology [28]. Examples of innovation platforms include Google Android, Apple iOS, and Amazon Web Services (AWS). We can also see hybrid companies that operate using both transaction and innovation platforms. For example, Amazon presents its marketplace as a transaction platform and its AWS as an innovation platform.

Platforms of either type adopt a unique architectural design that extends their functionality and sets them up for success and evolvability within a digital ecosystem [6]. The architectural design allows for mobilizing external users in a generative ecosystem [29], where large and diverse groups of actors produce unanticipated changes [30]. One of the defining features of this generative ecosystem is the multilateral interdependence across the actors and their activities [2]. Understanding this multilateral interdependence requires a more dynamic and holistic view of 
interactions in digital platforms and ecosystems. This view acknowledges high levels of complexity leading to various uncertainty challenges.

In the following sections, we refer to the innovation management literature to review extant research on uncertainty and related knowledge problems.

\subsection{Uncertainty in innovation}

In his seminal article, Dosi [31] considered the uncertain nature of inventive activity, one of the main aspects of the innovative process. The reason for such uncertainty is the unlimited and unknown sets of choices and outcomes. Uncertainty has been distinguished from risk, which is the lack of knowledge about probabilities [32]. These probabilities cannot be assigned in the case of uncertainty as they can be with risk. Thus, an unforeseeable notion of uncertainty can be defined as an organization's inability "to recognize the relevant influence variables and their functional relationships" [33: p. 1334].

Different areas of research have looked at uncertainty as a factor that influences organizational processes [34]-[36]. Other areas have looked at different manifestations of uncertainty in the innovation process. Uncertainty results from different sources such as technological complexity, competition, consumer behavior, or political or regulatory changes [37]-[39]. One of the common dimensions underlying many uncertainty studies is the level of uncertainty, i.e., whether it is a firm-specific uncertainty or a marketbased uncertainty [40]. Technological uncertainty related to the inventive process is an example of firmspecific uncertainties [41]. Perceived environmental uncertainty [35], such as regulatory uncertainty [37], is an example of market-based uncertainty that is external and shared across a set of firms.

Although it has been studied extensively in different streams of research, uncertainty as a concept still needs a better definition and a greater precision given the multidimensional nature of unknowingness. A recent review of the literature on knowledge problems and entrepreneurial action calls for establishing clearer boundary conditions among ambiguity, complexity, equivocality, and uncertainty as different manifestations of unknowingness [3]. In addition to the lack of conceptual precision, researchers have mainly relied on the varied empirical contextual factors to approximate the level of uncertainty.

Defining uncertainty as a problem of lack of knowledge implies that it can be reduced by increasing the availability of relevant information. Thus, theories on organizational learning and knowledge-based views of the firm are helpful to manage uncertainty and other knowledge-related problems [42]-[44]. Acquiring such knowledge, however, is not an easy process, especially in an innovation context. Innovation requires knowledge that varies in both depth and breadth, requiring a considerable set of knowledge components. The greater the set of knowledge components required, the higher the expected uncertainty or variability of the innovation outcomes [41].

\subsection{Knowledge problems}

Since one of our goals is to conceptualize the notion of uncertainty within the context of digital platforms and ecosystems, it is critical to understand relevant knowledge problems related to uncertainty. A knowledge problem denotes "an epistemological obstacle to strategic action that manifests in terms of the novelty being confronted along one or more dimensions of action, including what is being done, who is doing it, why they are doing it, and when, where, or how they are doing it." [3: p. 661]. In an entrepreneurship context, the notion of uncertainty has been distinguished from other knowledge problems that fall under the spectrum of unknowingness ranging from ignorance to certainty [3]. These knowledge problems are: (1) Ambiguity, wherein actors can predict potential outcomes of their decision based on the information they possess but cannot specify the probabilities of these multiple outcomes due to the opaqueness [45] or absence of relevant information [46]. This situation results in a multiplicity of impermanent interpretations [47] and incapability of sensemaking [48]; (2) Complexity, wherein numerous variables are involved in a problem and further interact with each other dynamically over time [49]. This complexity brings in inadequate understanding due to a lack of clear explanations; (3) Equivocality, wherein multiple meanings about organizational activities generate conflicting interpretations [50], whether presented individually or collectively [51].

These three knowledge problems (i.e., ambiguity, complexity, equivocality) differ from uncertainty "based on the typical structure of decision rules that reflect the role of information or the steps taken to resolve the knowledge problem" [3: p. 674]. While entrepreneurs can cope with the problem of uncertainty by increasing the amount of information through systematic search, ambiguity can only be managed through intersubjective agreement. In the case of complexity and equivocality, the increased amount of information may exacerbate knowledge problems [3].

In the context of digital platforms and ecosystems, uncertainty problems could require more than increasing the amount of available information. Different actors (e.g., owners, users, and regulators) may encounter epistemic uncertainties which can be resolved by advancing knowledge and understanding 
(e.g., increasing understanding regarding potential values that would be affected by technology during early design stages) [52]. Actors may also face ontological uncertainties derived from the mediation and extensibility characteristics of digital platforms, which cannot be managed by advancing knowledge or understanding [52]. To address such ontological uncertainties, de Reuver et al. [52] have suggested the consideration of the reflexivity phase within valuesensitive design (VSD). Initially, VSD methods help identify critical values during the design phase of new technologies, assuming that there is only epistemic uncertainty about which values will be affected by a technology. Reflexivity was suggested to cope with evolving ontological uncertainty in digital platforms. Reflexivity ensures enough flexibility in platform designs, wherein platform actors gain more information throughout the platform dynamic life cycle [52]. Consequently, actors can detect potential negative values generated by the employment of new technology.

It is essential to understand whether the knowledge problems fall under epistemic uncertainties or ontological uncertainties. This understanding could be achieved by paying close attention to the potential misdiagnosis of uncertainty as another knowledge problem, which results from the mismatch between the perceived knowledge problem and the actual knowledge problem [3]. Such misdiagnosis may mislead managerial decisions and result in financial loss.

To address this issue, we present an additional level of analysis to classify uncertainty in the platform context. The purpose of our classification is to distinguish among different dimensions of uncertainty based on the knowledge problems that dominantly contribute to their formation and the different actors facing such uncertainty in the digital platforms and ecosystems.

\section{Knowledge problems and the dimensions of uncertainty in digital platforms and ecosystems}

Given the dynamic nature of digital platforms and ecosystems where actors actively interact and implement innovative technologies within an open platform structure, multiple dimensions of the uncertainty problem have surfaced. Yet, it is still unclear how these uncertainty dimensions may manifest among the different groups of actors. Therefore, we utilize classification as "a fundamental mechanism for organizing knowledge" [54: p. 291] to categorize the different dimensions of uncertainty based on how they contribute to different actors' uncertainties. This section presents this further layer of classification along with relevant propositions on how different types of knowledge problems contribute to multiple dimensions of uncertainties among three main categories of actors in digital platforms and ecosystems: platform owners, users, and regulators.

Table 1 displays a summary of how different knowledge problems (i.e., complexity, equivocality, and ambiguity) act as dominant sources for the proposed dimensions of uncertainty among multiple actors within digital platforms and ecosystems.

Table 1 Dimensions of uncertainty and knowledge problems in digital platforms and ecosystems

\begin{tabular}{|c|c|c|c|}
\cline { 2 - 4 } \multicolumn{1}{c|}{} & \multicolumn{3}{|c|}{ Platform Actors } \\
\cline { 2 - 5 } \multicolumn{1}{c|}{$\begin{array}{c}\text { Uncertainty } \\
\text { Dimension(s) }\end{array}$} & $\begin{array}{c}\text { Resources, } \\
\text { Coordination, } \\
\text { Timing, } \\
\text { Market }\end{array}$ & $\begin{array}{c}\text { Technological, } \\
\text { Behavioral }\end{array}$ & Regulatory \\
\hline $\begin{array}{c}\text { Knowledge } \\
\text { Problems } \\
\text { (Source for } \\
\text { Uncertainty) }\end{array}$ & $\begin{array}{c}\text { Complexity } \\
\text { Regutors }\end{array}$ & Equivocality & Ambiguity \\
\hline Cause & $\begin{array}{c}\text { Lack of } \\
\text { explanations, } \\
\text { Abundance of } \\
\text { information on } \\
\text { elements and } \\
\text { their interactions }\end{array}$ & $\begin{array}{c}\text { Lack of } \\
\text { areement on } \\
\text { available } \\
\text { information }\end{array}$ & $\begin{array}{c}\text { Lack of clarity/ } \\
\text { opaqueness of } \\
\text { information in } \\
\text { dynamic states, } \\
\text { rich Information }\end{array}$ \\
\hline Effect & $\begin{array}{c}\text { Inadequate } \\
\text { understanding }\end{array}$ & $\begin{array}{c}\text { Multiple } \\
\text { conflicting } \\
\text { interpretations }\end{array}$ & $\begin{array}{c}\text { Multiple } \\
\text { impermanent } \\
\text { interpretations }\end{array}$ \\
\hline
\end{tabular}

The first platform actor category presented in Table 1 is the Platform Owners. The literature identifies four types of uncertainties that owners of digital platforms may have to manage in order to boost digital innovation capabilities [55]. They include (1) Resource uncertainty (i.e., uncertainty about how combined resources from multiple independent firms would create new value towards digital innovation ecosystem), (2) Coordination uncertainty (i.e., coordination of information and technologies to implement strategies mainly involving suppliers and customers), (3) Timing uncertainty (i.e., managing resources with the right scale in a timely manner) [53], and (4) Market uncertainty (i.e., the variability in demand for the firm's services or products) [56].

Resource uncertainty is inherent in the generative, combinatorial nature of the digital innovation processes carried out by large, varied, and uncoordinated actors [29], [57], [58]. This resource uncertainty is closely associated with coordination uncertainty given the different priorities and objectives of the actors in the platforms' ecosystem. Despite effective coordination 
and resource management, platforms can still be challenged by timing and market uncertainties caused by the need to understand and respond to market changes in a real-time manner. The lack of explanation of uncertainty elements and the constantly changing information within the innovative platform ecosystem could lead to a lack of understanding on how to manage such resources, coordination, timing, and market uncertainties [55]. For example, Homejoy, a cleaning services marketplace, has struggled to generate and maintain a reliable income for its service providers due to the actively changing supply and demand. The inadequate understanding of the market complicates the decision making. As a result, Homejoy was forced to shut down the business within less than 5 years after it was founded [59]. This example demonstrates the struggle to coordinate resources within a dynamic digital platform in a way that guarantees consistent flow in supply and demand. Therefore, we posit that:

Proposition 1: Complexity is the main factor that impacts resource, coordination, timing, and market uncertainties faced by platform owners within digital platforms and ecosystems.

The second platform actor category listed in Table 1 is the Platform Users. Platform users (e.g., service providers and service recipients) may encounter different forms of uncertainties including technological uncertainty and behavioral uncertainty. Technological uncertainty has been discussed in the literature at the firm level, wherein companies maintain conflicting sensemaking about the technological environment that is feasible to become dominant in the industry [60], [61]. Such type of uncertainty can be resolved by adopting a forward-looking approach to capture expected upcoming uncertainty that the firm may face rather than relying on historical information about the deployed technology [62].

Technological uncertainty is also experienced by the platform users: both the external third-party complementors, and the recipients of the complementary services. They gather information about fast-moving new platform-based technologies. As most of this information might be contradictory, users spend time and effort evaluating the complementarity services within these technologies. Conflicting interpretations among users challenge the decision-making about the ideal technology to utilize.

The second form of users' uncertainties in a platform setting is behavioral uncertainty, when actions and performance are hard to predict, which can also be referred to as a secondary uncertainty [63]. The behavioral dimension of uncertainties tends to evolve by the lack of agreement upon available information in both transaction and innovation platforms, which leads to the absence of cohesive interpretation needed to manage uncertain events. For example, Uber's and Airbnb's providers might have been able to address uncertainty issues related to the technological structure of the platform prior to or at the time of transaction, however, it might be a challenge to manage behavioral uncertainty experienced by the platform users (e.g., the sexual assault and abuse incidents on ride-sharing services) [64]. Therefore, platform users tend to disproportionately seek the most reputable service and product providers under high technological and behavioral uncertainty [65]. Hence, we propose:

Proposition 2: Equivocality is the key driver for technological and behavioral user uncertainties in digital platforms and ecosystems.

The third platform actor category illustrated in Table 1 is the Platform Regulators. Platform regulators face uncertainty in terms of policies governing platformbased businesses and industries [66]. The opaque or deficient information regarding digital platforms' boundaries in their dynamic states may result in a multiplicity of impermanent interpretations or even misinterpretations of the necessary regulations. Accordingly, the regulators are challenged to determine and enforce the necessary regulatory environment for the digital platforms and ecosystems [37]. In order to cope with this type of uncertainty, regulators need to collect information about digital platforms and ecosystems in their flux states. They must use creativity and imagination to predict and manage future uncertainties that they may face. Accordingly, we propose the following:

Proposition 3: Ambiguity related to the nature of platforms plays a major role in creating the uncertainty faced by the platform regulators.

To recap, this section presents a classification of uncertainties based on their source of knowledge problems including complexity, equivocality, and ambiguity. Given the fact that digital platforms may possess epistemological and ontological uncertainties, it is critical to clearly identify the type of knowledge problems related to these uncertainties.

\section{The dynamic interplay within the multidimensional uncertainty in digital platforms and ecosystems}

The different dimensions of uncertainty in digital platforms and ecosystems are not managed in isolation 
from each other. The growing complexity resulting from the distributed and multilateral nature of digital platforms and ecosystems implies dynamic and evolving interactions. Platforms and ecosystems uncertainty emerges in unique constellations depending on the history of interactions and sequences of actors' responses to their respective uncertainties.

Before we demonstrate a possible trajectory of these dynamic interactions, we recognize the need for a holistic definition of platforms and ecosystems uncertainty- here we define this concept as:

A path-dependent higher level of unpredictability that dynamically emerges from the interactions between the uncertainties experienced by the different actors in the platform ecosystem and how these actors respond to their respective uncertainties.

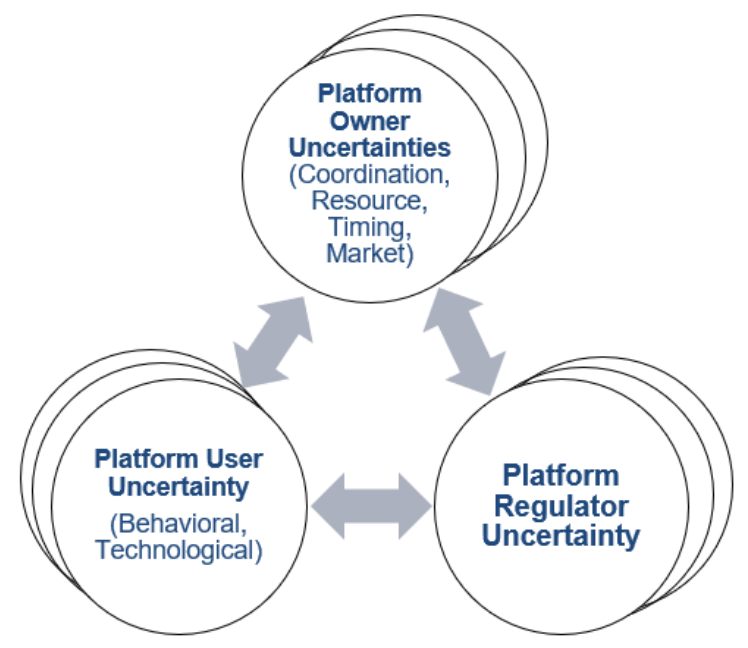

Figure 1 The dynamic interplay between different dimensions of uncertainties in digital platforms and ecosystems

Figure 1 demonstrates the dynamic interplay between the three proposed dimensions of platform uncertainties. The additional circles behind the three dimensions of uncertainty represent the influence of uncertainties experienced over time by the multiple actors. We speculate that the uncertainties experienced by the platform owners, the platform users, and the platform regulators may be modified in response to the other actors' actions while dealing with these uncertainties.

Constant challenges arise from these emergence and dependability features of different dimensions of uncertainties. For example, a buyer in a multi-sided platform encounters a behavioral uncertainty induced by the potential variability of offerings provided by the platform's sellers. Platforms, by design, are prone to instability in the quality of the collective offerings due to the reliance on third-party independent providers. This instability is particularly problematic if it involves offending and opportunistic behaviors such as fraud or misrepresentation. To cope with behavioral uncertainty, buyers on the platform want to have access to more sellers, to examine ratings and reviews by prior buyers, and to see evidence of seller's verification managed by the platform.

The behavioral uncertainties faced by the platform's users continuously shape the governance and control mechanisms applied by the platform owner. The mechanisms vary from the design of boundary resources that cultivate third-party providers development [67] to openness and gatekeeping decisions, two closely related strategic decisions implying the ease of restrictions to use or join the platforms [68]. However, these control and governance decisions could lead to resource uncertainty for the platform owner. From one side, the platform can lose the optimal balance in terms of user size on the different sides of the platform. This in turn might lead to network externality related to congestion on one side and scarcity on the other side. One of the ways the platform can respond to these resource uncertainties is by implementing temporary incentivizing strategies to balance supply and demand. An example of such strategies is surge pricing in ridesharing platforms.

While these incentives help put more drivers on the road, regulators worry about the number of working hours for drivers, i.e., exceeding 12 hours in a day. Such concern is closely linked to other aspects of platform labor regulations including providing insurance coverage to the drivers. Regulators such as the European Commission have been studying proposals to deal with regulatory uncertainties related to digital platforms. Their objective is to allow platforms to thrive while making sure users are treated fairly and conscientiously [69]. Imposing local domestic regulations on digital platforms contributes to the complexity of managing the platforms and ecosystems. Many platform-based firms, such as ride-sharing platforms, define themselves as players in the global technology industry rather than participants in a local transportation industry. Because of that, they do not agree with sectoral regulatory policies imposed by local courts.

The cycle continues as new platform owner uncertainties arise in response to the changing regulatory policies. In that way, the different dimensions of uncertainty and the way the multiple platform actors decide to respond to them emerge into different constellations of platform and ecosystem higher-level uncertainties. 


\section{Conclusion and insights for future research}

In this paper, we argued that complexity, equivocality, and ambiguity contribute to different dimensions of uncertainty in digital platforms and ecosystems. In doing so, we explain how the conceptualization of uncertainty is influenced by the structural aspects of digital platforms and ecosystems. Our contribution is threefold. First, we classify the dimensions of uncertainty in platforms and ecosystems based on the knowledge problem that dominantly contributes to these dimensions. Second, we conceptualize platforms and ecosystems uncertainty as a higher level of unpredictability concerning the multiple actors in the platform ecosystem. Third, we articulate the possible pattern by which this uncertainty emerges from the interactions among the actors' uncertainties and the way they choose to respond to them.

Future research may extend our classification of uncertainty dimensions by addressing different levels to categorize uncertainties in relation to other potential knowledge problems. In addition, we highlight several areas for extending and enhancing our research. One important avenue for research concerning the complexity of digital platforms and ecosystems. Some unexplored questions in this domain include:

- Considering the complexity and the multilateral interdependence in digital platforms and ecosystems, how may problems experienced by individual actors transform into a concern for the collective community over time?

- How is collective sensemaking in the context of digital platforms and ecosystems different from sensemaking in the traditional organizational context?

Ambiguity in digital platforms is another critical area that requires further investigation by incorporating the regulators' perspectives. Here are a few suggested questions:

- How can digital platforms introduce and apply appropriate scaling strategies while managing ambiguity levels for users and regulators?

- What are the effects of regulators' ambiguities on the potential growth of platforms and ecosystems?

- How can regulators institutionalize an adaptive set of regulations governing the dynamic digital platforms and ecosystems?

Equivocality in the context of digital platforms is also in a position for future research The following questions provide an initial proposal in that direction:

- What is the effect of equivocality among actors of the platform and ecosystem on the collective value creation and capture?
- How can the platform owner manage the equivocality problem among the actors of the platform and ecosystem?

Finally, uncertainty in digital platforms and ecosystems remains a critical topic that requires further examination due to its dynamic and evolving nature. The following questions could guide future research:

- What are the costs incurred by the platform due to excessive regulatory uncertainty? Regulatory delays? Or constant and incoherent legislative reviews?

- How can the platform utilize users' sense of community to manage behavioral uncertainty?

- What are the implications of platforms and ecosystems structural/relational characteristics on their users' technological and behavioral uncertainties? 


\section{References}

[1] P. Constantinides, O. Henfridsson, and G. G. Parker, "Platforms and infrastructures in the digital age," Inf. Syst. Res., vol. 29, no. 2, pp. 381-400, 2018, doi: 10.1287/isre.2018.0794.

[2] R. Adner, "Ecosystem as Structure: An Actionable Construct for Strategy," J. Manage., vol. 43, no. 1, pp. 39-58, 2017.

[3] D. M. Townsend, R. A. Hunt, J. S. McMullen, and S. D. Sarasvathy, "Uncertainty, knowledge problems, and entrepreneurial action," Acad. Manag. Ann., vol. 12, no. 2, pp. 659-687, 2018, doi: 10.5465/annals.2016.0109.

[4] A. Tiwana, B. Konsynski, and A. A. Bush, "Platform Evolution: Coevolution of Platform Architecture, Governance, and Environmental Dynamics," Inf. Syst. Res., vol. 21, no. 4, pp. 675687, 2010.

[5] B. Eaton, S. Elaluf-Calderwood, C. Sørensen, and Y. Yoo, "Distributed Tuning of Boundary Resources: The Case of Apple's iOS Service System," MIS Q., vol. 39, no. 1, pp. 217-243, 2015, doi: 10.25300/MISQ/2015/39.1.10.

[6] M. de Reuver, C. Sørensen, and R. C. Basole, "The digital platform: a research agenda," J. Inf. Technol., no. April, 2017, doi: 10.1057/s41265-016-0033-3.

[7] M. Cusumano and K. Nobeoka, Thinking Beyond Lean. Simon and Schuster., 1998.

[8] M. H. Meyer and A. P. Lehnerd, The power of product platforms. Simon and Schuster, 1997.

[9] A. Gawer and M. A. Cusumano, "Industry Platforms and Ecosystem Innovation," J. Prod. Innov. Manag., vol. 31, no. 3, pp. 417-433, 2013, doi:

10.1111/jpim.12105.

[10] C. Baldwin and K. Clark, Design rules: The power of modularity (Vol. 1). MIT press, 2000.

[11] M. Armstrong, "Competition in two-sided markets," RAND J. Econ., vol. 37, no. 3, pp. 668-691, 2006.

[12] D. S. Evans, "Some Empirical Aspects of Multisided Platform Industries," Rev. Netw. Econ., vol. 2, no. 3, pp. 191-209, 2003.

[13] A. Hagiu and J. Wright, "Marketplace or reseller?," Manage. Sci., vol. 61, no. 1, pp. 184-203, 2015, doi: 10.1287/mnsc.2014.2042.

[14] J.-C. Rochet and J. Tirole, "Two-sided markets : a progress report," RAND J. Econ., vol. 37, no. 3, pp. 645-667, 2006.

[15] M. L. Katz and C. Shapiro, "Systems Competition and Network Effects," vol. 8, no. 2, pp. 93-115, 1994.

[16] M. L. Katz and C. Shapiro, "Network Externalities, Competition, and Compatibility," Am. Econ. Rev., vol. 75, no. 3, pp. 424-440, 1985.

[17] G. Parker and M. Van Alstyne, "Two-Sided Network Effects: A Theory of Information Product Design," Manage. Sci., vol. 51, no. 10, pp. 14941504, 2005.

[18] M. Rysman, "The economics of two-sided markets," J. Econ. Perspect., vol. 23, no. 3, pp. 125-143,
2009.

[19] G. Parker, M. Van Alstyne, and S. P. Choudary, "Platform Revolution," WW Norton \& Company., $p$. 336, 2016.

[20] T. Eisenmann, G. Parker, and M. W. Van Alstyne, "Strategies for Two- Sided Markets," Harv. Bus. Rev., vol. 84, no. 10, p. 12, 2006.

[21] J. Hamari, M. Sjöklint, and A. Ukkonen, "The sharing economy: Why people participate in collaborative consumption," J. Assoc. Inf. Sci. Technol., vol. 67, no. 9, pp. 2047-2059, 2015.

[22] M. Cohen and A. Sundararajan, "Self-Regulation and Innovation in the Peer-to-Peer Sharing Economy," Univ. Chicago Law Rev., vol. 82, pp. 116-133, 2015.

[23] D. S. Evans, "Governing Bad Behavior by Users of Multi-Sided Platforms," Berkeley Tech. LJ, no. 582, 2011.

[24] J. Bosch, "From Software Product Lines to Software Ecosystems," in The 13th International Software Product Line Conference, 2009, pp. 111-119.

[25] A. Ghazawneh and O. Henfridsson, "Balancing platform control and external contribution in thirdparty development: The boundary resources model," Inf. Syst. J., vol. 23, no. 2, pp. 173-192, 2013.

[26] M. Kenney and J. Zysman, "The Rise of the Platform Economy," Sci. Technol., vol. 32, no. 3, pp. 61-69, 2016, doi: 10.17226/21913.

[27] M. A. Cusumano, A. Gawer, and D. B. Yoffie, The business of platforms: Strategy in the age of digital competition, innovation, and power. New York: Harper Business, 2019.

[28] R. Adner and R. Kapoor, "Value creation in innovation ecosystems: How the structure of technological interdependence affects firm performance in new technology generations," Strateg. Manag. J., vol. 31, no. 3, pp. 306-333, 2010.

[29] Y. Yoo, R. J. Boland, K. Lyytinen, and A. Majchrzak, "Organizing for innovation in the digitized world," Organ. Sci., vol. 23, no. 5, pp. 1398-1408, 2012, doi: 10.1287/orsc.1120.0771.

[30] J. L. Zittrain, "The generative Internet," Harv. Law Rev., vol. 119, no. 7, pp. 1974-2040, 2006.

[31] G. Dosi, "Technological paradigms and technological trajectories. A suggested interpretation of the determinants and directions of technical change," Res. Policy, vol. 11, no. 3, pp. 147-162, 1982, doi: 10.1016/0048-7333(82)90016-6.

[32] F. H. Knight, Risk, Uncertainty, and Profit. New York: Hart, Schaffner \& Marx, 1921.

[33] S. C. Sommer and C. H. Loch, "Selectionism and learning in projects with complexity and unforeseeable uncertainty," Manage. Sci., vol. 50, no. 10, pp. 1334-1347, 2004, doi: $10.1287 /$ mnsc. 1040.0274 .

[34] K. J. Boudreau, N. Lacetera, and K. R. Lakhani, "Incentives and problem uncertainty in innovation contests: An empirical analysis," Manage. Sci., vol. 57, no. 5, pp. 843-863, 2011, doi: $10.1287 / \mathrm{mnsc} .1110 .1322$. 
[35] F. J. Milliken, "Three Types of Perceived Uncertainty About the Environment : State, Effect, and Response Uncertainty," Acad. Manag. Rev., vol. 12, no. 1, pp. 133-143, 1987, doi: 10.5465/AMR.1987.4306502.

[36] S. Nambisan, "Digital Entrepreneurship: Toward a Digital Technology Perspective of

Entrepreneurship," Entrep. Theory Pract., vol. 41, no. 6, pp. 1029-1055, 2016, doi:

10.1111/etap.12254.

[37] V. H. Hoffmann, T. Trautmann, and J. Hamprecht, "Regulatory uncertainty: A reason to postpone investments? Not necessarily," J. Manag. Stud., vol. 46, no. 7, pp. 1227-1253, 2009, doi: 10.1111/j.1467-6486.2009.00866.x.

[38] A. Ortiz de Guinea and L. Raymond, "Enabling innovation in the face of uncertainty through IT ambidexterity: A fuzzy set qualitative comparative analysis of industrial service SMEs," Int. J. Inf. Manage., vol. 50, no. November 2018, pp. 244-260, 2020, doi: 10.1016/j.ijinfomgt.2019.05.007.

[39] S. C. Sommer, C. H. Loch, and J. Dong, "Managing complexity and unforeseeable uncertainty in startup companies: An empirical study," Organ. Sci., vol. 20, no. 1, pp. 118-133, 2009, doi:

10.1287/orsc. 1080.0369 .

[40] C. M. Beckman, P. R. Haunschild, and D. J. Phillips, "Friends or strangers? Firm-specific uncertainty, market uncertainty, and network partner selection," Organ. Sci., vol. 15, no. 3, 2004, doi: 10.1287/orsc. 1040.0065 .

[41] L. Fleming, "Recombinant uncertainty in technological search," Manage. Sci., vol. 47, no. 1, pp. 117-132, 2001, doi:

10.1287/mnsc.47.1.117.10671.

[42] J. G. . March, "Exploration and Exploitation in Organizational Learning," Organ. Sci., vol. 2, no. 1, pp. 71-87, 1991.

[43] G. P. . Huber, "Organizational Learning: The Contributing Processes and the Literatures," Organ. Sci., vol. 2, no. 1, pp. 88-115, 1991.

[44] I. Nonaka, "A Dynamic Theory of Organizational Knowledge Creation," Organ. Sci., vol. 5, no. 1, pp. 14-37, 1994, doi: 10.1287/orsc.5.1.14.

[45] D. van Stralen and T. Mercer, "Ambiguity in the Operator's Sense. Journal of Contingencies and Crisis Management," J. Contingencies Cris. Manag., vol. 23, no. 2, pp. 54-58, 2015.

[46] H. J. Holm, S. Opper, and V. Nee, "Entrepreneurs under uncertainty: An economic experiment in China," Manage. Sci., vol. 59, no. 7, pp. 1671-1687, 2013, doi: 10.1287/mnsc.1120.1670.

[47] K. E. Weick, "Ambiguity as Grasp: The Reworking of Sense," J. Contingencies Cris. Manag., vol. 23, no. 2, pp. 117-123, 2015, doi: 10.1111/14685973.12080.

[48] K. E. Weick, Sensemaking in organizations, Volume 3. 1995.

[49] P. Cilliers, Complexity and postmodernism: Understanding complex systems. Routledge, 2002.

[50] R. L. Daft and N. B. Macintosh, "A Tentative
Exploration into the Amount and Equivocality of Information Processing in Organizational Work Units," Adm. Sci. Q., vol. 26, no. 2, pp. 207-224, 1981.

[51] M. H. Zack, "If managing knowledge is the solution, then what's the problem?," in Knowledge management and business model innovation, IGI Global, 2001, pp. 16-36.

[52] M. de Reuver, A. van Wynsberghe, M. Janssen, and I. van de Poel, "Digital platforms and responsible innovation: expanding value sensitive design to overcome ontological uncertainty," Ethics Inf. Technol., vol. 22, no. 3, pp. 257-267, 2020, doi: 10.1007/s10676-020-09537-z.

[53] A. Gawer, Platforms, Markets and Innovation: An Introduction. Cheltenham, UK and Northampton, US: Edward Elgar, 2009.

[54] Y. Wand, D. E. Monarchi, J. Parsons, and C. C. Woo, "Theoretical foundations for conceptual modeling in information systems development.," Decis. Support Syst., vol. 15, no. 4, pp. 285-304, 1995.

[55] N. V. Venkatraman, P. A. Pavlou, O. A. El Sawy, and A. Bharadwaj, "Theorizing Digital Business Innovation: Platforms and Capabilities in Ecosystems," SSRN Electron. J., 2014, doi: 10.2139/ssrn.2510111.

[56] K. Blind, S. S. Petersen, and C. A. F. Riillo, "The impact of standards and regulation on innovation in uncertain markets," Res. Policy, vol. 46, no. 1, pp. 249-264, 2017, doi: 10.1016/j.respol.2016.11.003.

[57] S. Nambisan, K. Lyytinen, A. Majchrzak, and M. Song, "Digital Innovation Management : Reinventing Innovation Management Research," $M I S Q$., vol. 41, no. 1, pp. 223-238, 2017, doi: 10.25300/MISQ/2017/41.

[58] Y. Yoo, O. Henfridsson, and K. Lyytinen, "The new organizing logic of digital innovation: An agenda for information systems research," Inf. Syst. Res., vol. 21, no. 4, pp. 724-735, 2010, doi: 10.1287/isre.1100.0322.

[59] C. Farr, "Why Homejoy Failed," Wired, 2015. https://www.wired.com/2015/10/why-homejoyfailed/.

[60] P. Anderson and M. L. Tushman, "Organizational environments and industry exit: The effects of uncertainty, munificence and complexity," Ind. Corp. Chang., vol. 10, no. 3, pp. 675-710, 2001, doi: 10.1093/icc/10.3.675.

[61] R. Oriani and M. Sobrero, "Uncertainty and the market valuation of R\&D within a real options logic," Strateg. Manag. J., vol. 29, no. 4, pp. 343 361, 2008.

[62] P. K. Toh and T. Kim, "Why put all your eggs in one basket? A competition-based view of how technological uncertainty affects a firm's technological specialization," Organ. Sci., vol. 24, no. 4, pp. 1214-1236, 2013, doi: 10.1287/orsc. 1120.0782 .

[63] K. M. Sutcliffe and A. Zaheer, "Uncertainty in the transaction environment: an empirical test," Strateg. 
Manag. J., vol. 19, no. 1, pp. 1-23, 1998.

[64] S. O’Brien, "103 Uber drivers accused of sexual assault or abuse.," CNN, 2018.

http://money.cnn.com/2018/04/30/technology/uberdriver-sexual-assault/index.html.

[65] K. Taeuscher, "Uncertainty kills the long tail: demand concentration in peer-to-peer marketplaces," Electron. Mark., vol. 29, no. 4, pp. 649-660, 2019, doi: 10.1007/s12525-019-00339-w.

[66] W. J. Luther, "Regulatory ambiguity in the market for bitcoin," Rev. Austrian Econ., no. 2016, 2020, doi: 10.1007/s11138-019-00489-2.

[67] A. Ghazawneh and O. Henfridsson, "Balancing platform control and external contribution in thirdparty development: the boundary resources model," pp. 173-192, 2013, doi: 10.1111/j.13652575.2012.00406.x.

[68] K. J. Boudreau and L. B. Jeppesen, "Unpaid crowd complementors: The platform network effect mirage," Manag. J., vol. 36, no. 12, pp. 1761-1777, 2015, doi: 10.1002/smj.

[69] "Proposal for a regulation. Digital Services Act package - ex ante regulatory instrument of very large online platforms acting as gatekeepers.," European Commission, 2020.

https://ec.europa.eu/info/law/better-regulation/haveyour-say/initiatives/12418-Digital-Services-Actpackage-ex-ante-regulatory-instrument-of- verylarge-online-platforms-acting-as-gatekeepers. 